\title{
Recurrence of pulsus alternans after fentanyl injection in a patient with aortic stenosis and congestive heart
} Andrew B. Freeman MD, Richard A. Steinbrook mD faillie

Following aortic valve replacement in a patient with aortic stenosis and cardiac failure, marked pulsus alternans recurred immediately after intravenous injection of $0.5 \mathrm{mg}$ fentanyl, without concomitant changes in heart rate, mean left atrial pressure, or the electrocardiogram. Pulsus alternans is known to occur in association with heart failure and aortic stenosis, but has not been reported previously in response to anaesthetic drugs. Mechanisms of pulsus alternans are discussed, and the possible contributory role of fentanyl is considered.

Pulses alternans, the alternation of ventricular systoles of greater and lesser power, is well documented in the medical literature. It is known to occur most commonly in individuals with heart failure, especially in association with acquired aortic stenosis. ${ }^{1,2}$ A relationship between anaesthetic drug administration and pulsus alternans has not been reported. In this report we describe the

\section{Key words}

ANALGESICS: fentanyl; SURGERY: cardiac; BLOOD PRESSURE: drug effects, fentanyl.

From the Departments of Anaesthesia, Brigham and Women's Hospital and Haryard Medical School, Boston, MA.

Address correspondence to: Dr. Richard A. Steinbrook, Department of Anesthesia, Brigham and Women's Hospital, 75 Francis Street, Boston, MA 02115 . recurrence of pulsus altemans after the intravenous bolus injection of $0.5 \mathrm{mg}$ fentanyl in a patient with aortic stenosis and cardiac failure.

\section{Case report}

An 82-year-old $65-\mathrm{kg}$ man was scheduled for aortic valve replacement for acquired aortic stenosis. He had an eight year history of progressive dyspnea on exertion, wheezing, paroxysmal nocturnal dyspnea, and episodes of near syncope. His medications were digoxin ( $0.125 \mathrm{mg}$ p.o. daily), furosemide, and spironolactone. The electrocardiogram showed sinus rhythm with first degree AV block and left bundle branch block. The haematocrit was 40.0 per cent; serum potassium was $4.4 \mathrm{mEq} \cdot \mathrm{L}^{-1}$. Cardiac catheterization revealed a diffusely hypokinetic and enlarged left ventricle; cardiac index was $1.7 \mathrm{~L} \cdot \mathrm{min}^{-1} \cdot \mathrm{m}^{-2}$, with a peak systolic left-ventricular-to-aortic pressure gradient of $30 \mathrm{mmHg}$ and calculated aortic valve area of $0.5 \mathrm{~cm}^{2}$

After premedication with lorazepam $2 \mathrm{mg}$ p.o., the patient was brought to the operating room where radial arterial and internal jugular catheters were inserted. Pre-induction vital signs included arterial blood pressure of $100 / 45$ with beat-to-beat alternation in systolic blood pressure (pulsus alternans) of less than $15 \mathrm{mmHg}$, sinus rhythm of 75 per minute, and central venous pressure of $1 \mathrm{mmHg}$. Continuous recording of electrocardiogram and arterial pressure was instituted.

Following preoxygenation, general anaesthesia was induced with incremental doses of fentanyl, 


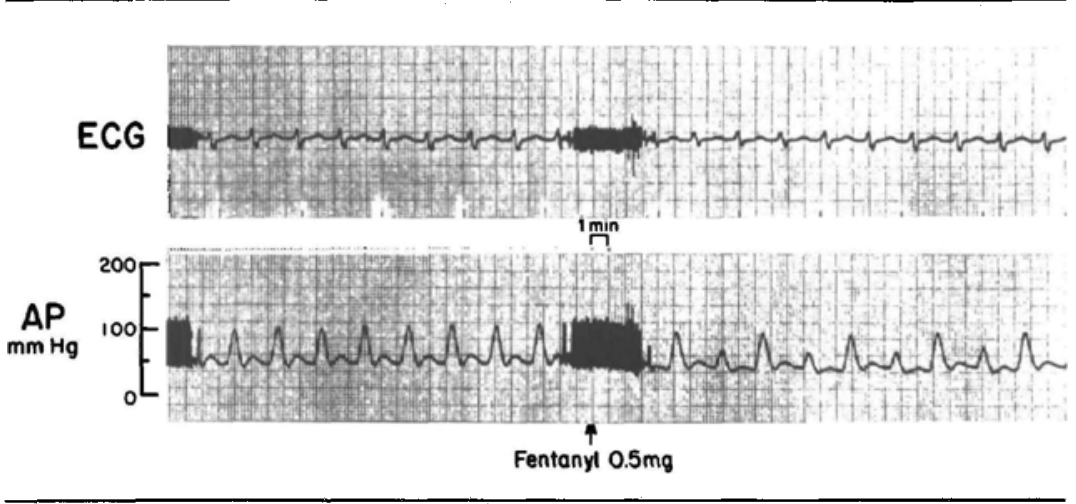

FIGURE Pulsus alternans associated with administration of $0.5 \mathrm{mg}$ fentanyl shorty after aortic valve replacement. Continuous recording; paper speed $5 \mathrm{~mm} / \mathrm{min}$ in center of tracing (as shown by "1 $\mathrm{min}$ " scale), and $25 \mathrm{~mm} / \mathrm{sec}$ otherwise. See text for details $\mathrm{ECO}=$ electrocardiogram; $\mathrm{AP}=$ systemic arterial pressure:

pancuronium, and diazepam, until a total of 1.85 $\mathrm{mg}, 10 \mathrm{mg}$, and $10 \mathrm{mg}$, respectively, were administered. Lactated Ringer's solution was infused to maintain central venous pressure of $10 \mathrm{mmHg}$; urine output was greater than $0.5 \mathrm{ml} \cdot \mathrm{kg}^{-1} \cdot \mathrm{hr}^{-1}$. The pre-bypass period was notable for continued pulsus alternans of $10-15 \mathrm{mmHg}$. Additional fentanyl $(1.0 \mathrm{mg})$ was administered during cardiopulmonary bypass. The heavily calcified tricuspid aortic valve was replaced with a $27 \mathrm{~mm}$ CarpentierEdwards porcine bioprosthesis. After an uneventful period of cardiopulmonary bypass, sinus thythm was re-established. A catheter placed into the left atrium was attached to a fluid-filled manometer on the surgical field for continuous monitoring of left atrial pressure after bypass. Ventricular ectopy and hypertension were controlled by continuous infusion of lidocaine ( $2 \mathrm{mg} \cdot \mathrm{min}^{-1}$ ) and nitroprusside $\left(<2 \mu \mathrm{g} \cdot \mathrm{kg}^{-1} \cdot \mathrm{min}^{-1}\right)$. Systolic blood pressure ranged from 110 to $120 \mathrm{mmHg}$, left atrial pressure from 5 to $10 \mathrm{~cm}$ water, heart rate from 100 to 115 , and there was no pulsus alternans (Figure). Urine output after bypass exceeded $1 \mathrm{ml} \cdot \mathrm{kg}^{-1} \mathrm{hr}^{-1}$. Following sternal wiring but before skin closure, more than one hour after starting lidocaine and nitroprusside, a bolus of $0.5 \mathrm{mg}$ of fentanyl was injected. This was followed almost immediately by the appearance of pulsus alternans of $30 \mathrm{mmHg}$ systolic (Figure). There were no changes in the electrocardiogram, heart rate, or mean left atrial pressure, which was $8 \mathrm{~cm}$ water. Pulsus altemans continued for at least 30 minutes, at which time management was transferted to the intensive care team. Postoperative recovery was slow with evidence of continued congestive heart failure. The patient was discharged 15 days after surgery.

\section{Discussion}

Pulsus alternans has long been recognized in association with aortic stenosis. Usually indicative of severe aortic stenosis, pulsus alternans is more often observed with acquired aortic stenosis than with congenital aortic stenosis of comparable severity. Pulsus alternans of 20 to $30 \mathrm{mmHg}$ may be present in the left ventricle with minimal alternans apparent in peripheral arterial pulses. ${ }^{1,2}$

Pulsus alternans should not be confused with bigeminal pulse, a far more common cause of alternating arterial pulsations. Bigeminal pulse is produced by coupling of a premature (weaker) beat with a normal (stronger) beat. In pulsus alternans, the beat to beat interval is constant.

The mechanism of generation of pulsus alternans has not been established. Incomplete recovery of contractile cells, with alternate failure of contraction has been postulated. Extracardiac factors causing alternation in ventricular filling have also been proposed. $^{3}$

Friedman et $a l^{4}$ studied three patients with advanced heart disease in whom pulsus alternans could be induced by phlebotomy or by assumption of an erect position; pulsus alternans was mini- 
mized or abolished by exercise, digitalis, and norepinephrine infusion. These investigators concluded that in these patients with diseased hearts, reductions in end-diastolic volume by diminished venous return resulted in sub-optimal ventricular contraction. With a weak contraction, end-systolic volume was increased, leading to an increase in end-diastolic volume and a stronger contraction on the next beat. Such alternation of end-diastolic volume was observed by Gleason and Braunwald ${ }^{5}$ during angiography in a patient with congenital aortic stenosis. Additional evidence in support of alternating end-diastolic fibre length as a cause of pulsus alternans is provided in the experimental study of Mitchell et al. in dogs. ${ }^{3}$ A more recent study by McGaughey et al. ${ }^{6}$ in isolated dog hearts showed that alternating end-diastolic volume is not the only determining factor, as beats with identical end-diastolic volume still resulted in different endsystolic volumes and pressures, depending on the contractile state of the myocardium.

Several factors may have been responsible for the recurrence of pulsus alternans in our patient. First, myocardial contractility may have been altered as a result of myocardial infarction of air in a coronary artery. This was unlikely as the electrocardiogram showed no changes, either at the time of recurrence of pulsus alternans or subsequently, and serum enzyme levels postoperatively did not indicate myocardial infarction. Second, premature ventricular contractions are known to initiate pulsus alternans. However, lidocaine infusion had abolished ventricular ectopy for more than 30 minutes prior to the recurrence of pulsus alternans. Third, nitroprusside may produce changes in systemic venous return, resulting in pulsus alternans. Such was unlikely in view of the unchanged left atrial pressure at the time of recurrence of pulsus alternans.

Fentanyl as a cause of pulsus alternans is strongly suggested by the temporal relationship between the administration of fentanyl and the return of pulsus alternans in this susceptible patient. Although pulsus alternans could have recurred spontaneously, the abrupt onset immediately after fentanyl, the magnitude of the pulsus alternans (more than twice that noted previously), and the absence of any concurrent changes in patient position or degree of surgical stimulation suggest a cause and effect relationship. To our knowledge such a response to fentanyl has not previously been reported. Indeed, fentanyl is generally considered to have minimal haemodynamic effects in patients with valvular heart disease. ${ }^{7,8}$

The mechanisms by which fentanyl administration induced pulsus alternans must be consistent with the observed heart rate, rhythm, and left atrial pressure, all of which were unchanged after fentanyl. We propose that a decrease in sympathetic tone produced by fentanyl resulted in the recurrence of pulsus alternans in this patient. Reductions in plasma concentrations of epinephrine and norepinephrine, presumably reflecting a decrease in sympathetic tone, have been demonstrated in response to fentanyl $\left(75 \mu \mathrm{g} \cdot \mathrm{kg}^{-1}\right)$ prior to cardiopulmonary bypass in patients undergoing coronary-artery bypass surgery. ${ }^{9}$ Our patient received a total fentanyl dose of $52 \mu \mathrm{g} \cdot \mathrm{kg}^{-1}$.

Changes in sympathetic tone have widespread effects, and pulsus alternans may have been brought about by either a reduction in cardiac sympathetic or vascular sympathetic tone, or both. Although beatto-beat change in preload may not have been detected by the relatively sluggish manometric method employed here, the lack of change in preload as measured by left atrial pressure suggests that a vascular tone change was not responsible.

We are unable to say how withdrawal of sympathetic tone might have been responsible for pulsus alternans. However, it is of interest that manoeuvres which increase sympathetic tone such as exercise, ${ }^{4}$ norepinephrine infusion ${ }^{3,4}$ or reflex cardiac sympathetic nerve stimulation ${ }^{3}$ can abolish pulsus alternans. These manipulations have cardiac sympathetic stimulation as the common denominator

In summary, we have described the appearance of pulsus alternans immediately after fentanyl administration in a patient undergoing aortic valve replacement. We speculate that a reduction in sympathetic tone induced by fentanyl was responsible for the pulsus alternans. Although our patient suffered no apparent ill effects as a result, this case report illustrates a potentially significant haemodynamic effect of fentanyl. 


\section{References}

1 Cooper T, Braunwald E, Morrow AG. Pulsus alternans in aortic stenosis: hemodynamic observations in $\mathbf{5 0}$ patients studied by left heart catheterization. Circulation 1958; 18: 64-70.

2 Hancock EW, Fleming PR. Aortic stenosis. Quarterly Journal of Medicine. 1960; 29: 209-34.

3 Mitchell JH, Sarnoff SJ, Sonnenblick EH. The dynamics of pulsus altemans: alternating enddiastolic fiber length as a causative factor. J Clin Invest 1963; 42: 55-63.

4 Friedman B, Daily WM, Sheffield RS. Orthostatic factors in pulsus alternans. Circulation 1953; 8 : 864-73.

5 Gleason WL, Braunwald E. Studies on Starling's law of the heart. VI. Relationships between left ventricular end-diastolic volume and stroke volume in man with observations on the mechanism of pulsus alternans. Circulation 1962; 25: 841-8.

6 McGaughey $M D$, Maughan WL, Sunagawa $K$, Sagawa $K$. Alternating contractility in pulsus alternans studied in the isolated canine heart. Circulation 1985; 71: 357-62.

7 Stoelting RK, Gibbs PS, Creasser CW, Peterson C. Hemodynarnic and ventilatory responses to fentanyl, fentanyl-droperidol, and nitrous oxide in patients with acquired valvular heart disease. Anesthesiology 1975; 42: 319-24.

8 Bovill JG, Warren PJ, Schuller $J$, van Wezel $H B$, Hoeneveld $M H$. Comparison of fentanyl, sufentanil, and altentanil anesthesia in patients undergoing valvular heart surgery. Anesth Analg 1984; 63: 1081-6.

9 Stanley TH, Berman L, Green O, Robertson D. Plasma catecholamine and cortisol responses to fentanyl-oxygen anesthesia for coronary-artery operations. Anesthesiology 1980; 53: 250-3.
Résumé

Après remplacement valvulaire aortique chez un patient se présentant pour une sténose aortique et insuffisance cardiaque, un pouls alternant marqué a réapparu im. médiatement après l'administration intraveineuse de $0.5 \mathrm{mg}$ de fentanyl, et ce sans aucun changement concomitant da la fréquence cardiaque, la pression moyenne de l'areillette gauche ou de l'électrocardiogramme. Un pouls alternant est observé en assaciation avec l' insuffisance cardiaque et la sténose aortique mais n'o jamais été rapporté après l'administration d'agents anesthésiques. Les mécanismes du pouls alternant et le rôle possible du fentanyl sont discutés. 